\title{
o Romper el silencio: necesidades de información y comunicación de los migrantes centroamericanos en México
}

\section{Guillermo Barros' Universidad de Deusto (España)}

Resumen: La expansión de la violencia en Centroamérica ha diversificado el perfil de las personas forzadas a huir de sus países. Los refugiados y otros migrantes indocumentados tienen diferentes nacionalidades, edades o nivel socioeconómico. Pero todos coinciden en algo: necesitan información confiable para tomar decisiones en una travesía extremadamente peligrosa. Este trabajo radiografía las necesidades de información de los migrantes, sus medios y recursos para cubrirlas y el papel que juegan las tecnologías para ayudarles 0 ponerles más en riesgo. La investigación expone que la comunicación es una prioridad y que muchos prefieren invertir sus escasos recursos en contactar con su familia antes que en comida o alojamiento. La mayoría viaja con un celular o pretende conseguir uno, se conecta a redes sociales y comienza a usar aplicaciones como Google Maps. Mayoritariamente jóvenes y urbanos, los migrantes centroamericanos tienen cada vez más conocimientos para aprovechar las posibilidades de estas herramientas digitales.

Palabras clave: migración, derechos humanos, nuevas tecnologías, información, comunicación, protección, Centroamérica, México.

Abstract: The spread of violence in Central America has diversified the profile of people forced to flee their countries. Refugees and other undocumented migrants have different nationalities, ages or socio-economic status. But they all agree on something: they need reliable information to make decisions on an extremely dangerous journey. This research analyzes the information needs of migrants, their ways and resources to cover them and the role of technologies to help them or put them at greater risk. The study concludes that communication is 
a priority and many prefer invest their scant economical resources to be in touch with their families over food or shelter. Most of the interviewees were travelling with their own cell phones or wanted to get one. They were connected to social networks and starting to use apps like Google Maps. Mainly young and urban, migrants are gaining more knowledge to take advantage of these digital tools.

Key words: migration, human rights, new technologies, information, communication, protection, Central America, Mexico.

\section{Introducción}

En los últimos años, el acceso a la información y la tecnología se ha convertido en una prioridad del trabajo humanitario, como lo es proporcionar comida, agua y refugio (Federación Internacional de Sociedades de la Cruz Roja y la Media Luna Roja, 2013, p.11). El uso de mensajes SMS o vía Twitter ha ayudado a salvar vidas en contextos de inseguridad y desastres naturales en muchas partes del mundo, desde Haití hasta Filipinas (Meier, 2015, p. 28). En México, no obstante, todavía no se han explorado las posibilidades que abren las nuevas tecnologías para ayudar y socorrer a los centenares de miles de refugiados y otros migrantes que cada año ingresan irregularmente a su territorio. Para intentarlo se requiere tener mucha más información de la que disponemos actualmente sobre el contexto de precariedad e inseguridad en el que se mueven y también más datos de los propios migrantes. La gran mayoría de ellos procede de Guatemala, Honduras y El Salvador; el llamado Triángulo Norte centroamericano, una de las regiones más violentas del mundo que soporta los índices de homicidios más altos de cualquier lugar donde no exista una guerra convencional (ONU, 2015).

Esta investigación está basada en 40 entrevistas con solicitantes de asilo y otros migrantes procedentes de El Salvador, Guatemala y Honduras realizadas en septiembre de 2016, dos puntos de México que son clave en el tránsito de indocumentados. En el texto se intercalan testimonios de los entrevistados para que expresen sus experiencias y reflexiones con sus propias palabras, sin intermediarios. El estudio se concentra en los migrantes del Triángulo Norte, una región de unos 30 millones de habitantes, por dos razones principales: la primera es que de estos tres países procede la inmensa mayoría de los indocumentados detenidos en México, en concreto fueron el 92\% del total en 2015 (Paullier, 2016). Y la segunda es porque existe la necesidad de que las 
organizaciones civiles incrementen la respuesta ante el fenómeno del desplazamiento forzoso provocado por la criminalidad en el Triángulo Norte, que para ACNUR constituye toda una "crisis humanitaria". Frente a ello, los Estados y las organizaciones internacionales siguen identificando al crimen organizado como un desafío de seguridad nacional obviando sus consecuencias humanitarias y la necesidad de dar una protección internacional integral a las víctimas (ACNUR, 2012, p. 7). La muestra está conformada por 40 migrantes centroamericanos de entre 14 y 53 años con variedad de nacionalidades, género, niveles socioeconómicos, estudios y motivos de salida de su país. Entre los entrevistados, 27 proceden de Honduras, 5 de El Salvador y 8 de Guatemala. Por géneros, 30 son hombres y 10 mujeres, también se incluyen tres menores de edad y tres miembros de la comunidad LGBTI (personas Lesbianas, Gays, Bisexuales, Transgénero e Intersexuales). Las entrevistas se llevaron a cabo en el Hogar Refugio para personas migrantes La 72 de Tenosique (estado de Tabasco, sureste) y en el albergue Belén Posada del Migrante de Saltillo (estado de Coahuila, norte).

\section{Perfil de la migración hacia Estados Unidos}

Los patrones de la migración de Norte y Centroamérica hacia Estados Unidos han variado notablemente en la última década: mientras la migración desde México ha descendido a mínimos históricos, la de los tres países del Triángulo Norte se ha incrementado (Migration Policy Institute, 2015, p. 3). El fenómeno está vinculado con el deterioro de las condiciones de vida en Honduras, Guatemala y El Salvador. El fortalecimiento de las pandillas (conocidas en la región como "maras") y otros actores armados, la expansión de los delitos a todas las capas de la sociedad, la debilidad de los Estados, la falta de empleo, la pobreza y desigualdad crónica son las principales causas del éxodo. ACNUR viene registrando un aumento creciente del número de personas de El Salvador, Guatemala y Honduras que piden refugio, mayoritariamente en Estados Unidos pero también en México y en otros países del continente. El volumen de desplazamiento en Centroamérica ha alcanzado niveles que no se veían desde los conflictos armados de la década de los ochenta.

En México, el flujo de emigración centroamericana se ha incrementado un $286 \%$ entre 2012 y 2016 , y se estima que ya son más de 400,000 
personas las que ingresan cada año irregularmente por su frontera sur para iniciar un trayecto en el que peligra su integridad y su vida. ${ }^{3}$ La magnitud de la violencia que afrontan, sin embargo, se desconoce. Pocos indocumentados se atreven a denunciar los delitos de los que son víctima por temor a la deportación o a la complicidad de los funcionarios con los criminales. Organismos de derechos humanos han documentado una gran variedad de delitos cometidos contra solicitantes de asilo y migrantes, entre ellos: robo, extorsión, explotación laboral y sexual, asesinatos y desapariciones. La mayoría de los crímenes son perpetrados por la delincuencia organizada pero se han documentado muchos casos de involucramiento de policías y de otras autoridades (Comisión Interamericana de Derechos Humanos, 2015, p. 132).

En los últimos años, las organizaciones civiles mexicanas han alertado de un aumento de las violaciones a los derechos humanos de los migrantes a raíz de la implementación en 2014 de un plan gubernamental de seguridad conocido como Programa Frontera Sur. Este operativo, que incluyó el despliegue del Ejército, se lanzó coincidiendo con la alarma generada en Estados Unidos por una ola de menores centroamericanos que llegaban solos a su frontera sur. Organizaciones civiles como
WOLA (Oficina en Washington para Asuntos Latinoamericanos) han señalado que el Programa Frontera Sur parece haber sido implementado por presiones de Washington para incrementar las detenciones y las deportaciones en México y que los migrantes no pudieran llegar a Estados Unidos ni pedir asilo allí (WOLA, 2015, p. 8). El operativo, alertan WOLA y otras ONG, provocó que los migrantes tuvieran que buscar rutas y medios de transporte alternativos en México para sortear los controles migratorios, incluido el traslado a pie, lo que les convierte en un objetivo más sencillo para los grupos criminales. Estos cambios han trastocado el mapa de la migración mexicana y han hecho que menos personas lleguen a los refugios ubicados a lo largo de la ruta del tren de carga en el que tradicionalmente han viajado como polizones, conocido como "La Bestia". En esos refugios, los migrantes encuentran alojamiento, alimentación, seguridad y asistencia. Sin ese contacto con las organizaciones que les apoyan, los migrantes pierden la oportunidad de recibir una información valiosa para su camino, así como de comunicar su ubicación a sus familias. Alejados de la red de ayuda humanitaria creada a lo largo de los años alrededor de las vías del tren, resulta mucho más difícil ahora establecer el paradero de los migrantes si en algún momento se pierde el contacto con ellos. 


\section{Nuevas tecnologías y migración}

A lo largo de los últimos 25 años, la expansión de Internet, la difusión de los teléfonos celulares $y$ el auge de las redes sociales han transformado la vida en las sociedades industrializadas y en desarrollo. La información circula en mayor cantidad y más libremente que nunca en un mundo interconectado en tiempo real. Sin embargo, ese no es el mundo de los migrantes indocumentados, los desplazados y los refugiados. La vulnerabilidad que padecen y la clandestinidad en la que se mueven dificultan tanto que se puedan comunicar libremente como que ellos mismos puedan ser localizados por sus familias en caso de pérdida de contacto. En otro tipo de situaciones de crisis, las tecnologías ya están jugando un papel clave para la ayuda humanitaria. Personas en zonas afectadas por desastres están pudiendo comunicarse más entre ellas y con los actores humanitarios, generando una circulación en tiempo real de información que puede ayudar a salvar vidas. Redes sociales como Facebook o Twitter son utilizadas para crear sistemas de alerta temprana de desastres, pedir asistencia urgente, buscar información o comunicarse con sus allegados o con agencias estatales $O$ humanitarias. El abanico de posibilidades de las nuevas tecnologías para informar, comunicar $y$ ofrecer servicios a los beneficiarios de la ayuda humanitaria es enorme, como también lo son sus riesgos y costes en contextos de inseguridad, como se verá más adelante.

El Big Data -el masivo volumen de datos generado y recopilado por gobiernos, sector privado y sociedad civil- puede ser aplicado también para fines humanitarios. Los datos crudos generados a través de las redes sociales o los Sistemas de Información Geográficos (GIS, por sus siglas en inglés), como imágenes de satélite o movimientos de teléfonos celulares, tienen el potencial de ser analizados y transformados en información útil para la toma de decisiones que puede ser compartida con otros actores humanitarios y con los propios beneficiarios. Un estudio divulgado en 2012, por ejemplo, demostró que con un monitoreo en tiempo real de los mensajes de Twitter en Haití se hubiera podido detectar el brote de cólera de 2010 dos semanas antes de lo que se hizo, lo que posiblemente hubiera salvado vidas (OCHA, 2012, p. 27). Entre las experiencias positivas, el uso de Twitter tras el terremoto de Filipinas de 2012 ayudó a que decenas de personas fueron rescatadas de los escombros 
gracias a que familiares o vecinos alertaron de su situación por esa red social. Para refugiados y solicitantes de asilo existen también iniciativas incipientes de apoyo digital. En Costa Rica, ACNUR creó un sitio electrónico (Ayuda. Acnur) dirigido especialmente a este colectivo. Esta web pretende suministrar la información mínima que requiere ese colectivo para establecerse en un nuevo país: su estatus legal, derechos y obligaciones, alojamiento, educación, oportunidades de empleo, programas de apoyo, entre otros. Para los solicitantes de asilo o refugiados, poder acceder a ese volumen de información por vía electrónica puede resultar más rápido y barato que hacer una llamada o desplazarse en persona a una oficina. Básicamente se requiere acceso a Internet y a una computadora o a un teléfono inteligente, lo cual cada vez está más al alcance de algunos refugiados. Los desplazados sirios, por ejemplo, se han convertido en un ejemplo del uso de esas tecnologías para moverse por rutas de alta inseguridad. Estos refugiados emplean Google Maps para guiarse, comparten información útil por Facebook, contactan con personas que les pueden ayudar, localizan lugares donde comer y dormir, informan a sus familias de su situación y toman fotos y vídeos de asaltos que suben a redes sociales.

\section{Informarse y comunicarse en la ruta migratoria}

Después de explorar el contexto migratorio y las tecnologías aplicadas al mundo humanitario, este capítulo se adentra en las necesidades y las características de la comunicación de un colectivo en concreto: los centroamericanos que transitan irregularmente por México. En términos generales, el estudio no discrimina entre los migrantes cuya intención es avanzar clandestinamente por México hasta llegar a la frontera con Estados Unidos y aquellos que, cada vez en mayor número, inician un proceso de solicitud de asilo o de visa humanitaria buscando protección internacional en el país latinoamericano. En lo que se refiere al ámbito de la información y la comunicación, no existen grandes diferencias entre estos dos grupos. Como se observará, ambos colectivos afrontan similares niveles de precariedad, desinformación y riesgo. Dentro del flujo migratorio centroamericano en México, la capacidad económica y el contacto con un "coyote" (traficante de personas) confiable son variables que influyen mucho más en la seguridad de las comunicaciones, y en la seguridad del viaje en general, que su estatus legal. 
4.1 Necesidades de información

A pesar de que la ruta migratoria por México es una de las más peligrosas del mundo, son pocos los entrevistados que buscaron información activamente antes de comenzar su viaje. La gran mayoría decidió, o se vio forzado, a salir de sus países sin una idea clara de a qué se iba a enfrentar en su camino hacia algún lugar más próspero y seguro. Una parte de ellos ya había viajado hacia Estados Unidos con anterioridad, una o varias veces, y consideraba que ese conocimiento resultaría suficiente, si bien las condiciones en México no siempre son las mismas, ni los migrantes toman siempre la misma ruta. Otros entrevistados se fiaron del conocimiento que les transmitieron familiares o conocidos que habían superado esa ruta, algunos de los cuales estaban en Estados Unidos y otros de regreso a sus lugares de origen por decisión propia o por deportación. Básicamente, se trata de unas primeras y vagas indicaciones para los tramos iniciales del viaje. El migrante y su fuente se citan para seguir en comunicación a lo largo de la ruta, lo cual no siempre acaba siendo posible. También hubo quien salió de su país junto a otras personas, entre las cuales alguna conocía el camino, o bien el grupo contrató directamente un "coyote". Dos últimos tipos de migrantes cierran el recuento con unas características muy significativas y de especial vulnerabilidad. El primer grupo son los que tuvieron que huir apresuradamente de sus casas por amenazas directas o indirectas de grupos armados y que no tuvieron tiempo de hacer ningún preparativo.

En Guatemala ni siquiera sabíamos qué ruta agarrar. Preguntamos y la gente al ver que uno no conoce a veces también se aprovecha de eso. Te dicen tanto te cuesta viajar a tal lado' y como uno no conoce tiene que pagar, pagar, pagar hasta llegar al punto.

(Júnior. 23 años, El Salvador. Estudiante universitario que tuvo que huir con su hermano menor y su tío por amenazas de muerte de una mara a su hermano).

El otro grupo de alta vulnerabilidad son aquellos migrantes que simplemente parten asumiendo que enfrentarán con pocos recursos un camino desconocido y plagado de peligros, y no creen que ninguna información previa pueda ayudarles a evitar esos riesgos. 
No busqué nada, uno ya sabe a lo que viene. Si no traes dinero no te queda otra más que viajar en el tren. $Y$ si agarras el tren te vas a exponer a lo que te pueda pasar.

(Marvin. 38 años, Honduras. Emigró en solitario para huir de la pobreza).

Según los testimonios recogidos, estos son los principales puntos de interés informativo para los migrantes:

- Zonas de mayor inseguridad para la migración por presencia de grupos armados.

- Puntos de control migratorio, policial y militar.

- Corrupción policial y coste de las "mordidas" (sobornos) a pagar para poder avanzar en la ruta.

- Características de los tramos que se tienen que hacer caminando (distancias a pie, condiciones climáticas, cantidades de agua y alimentos necesarios...).

- Requisitos para solicitar el refugio o la visa humanitaria y qué restricciones implica, principalmente si les prohíbe volver a su país.

- Duración de los trámites y estado de sus solicitudes.

\subsubsection{Fuentes directas de información}

Las principales fuentes de información con las que cuentan los migrantes del Triángulo Norte siguen siendo las fuentes directas: personas de su familia o entorno cercano que les relatan sus experiencias de un camino que ha sido recorrido por centroamericanos por décadas. Como mencionábamos, los datos que les aportan son en muchos casos insuficientes o desactualizados.

Es común que el migrante acuerde con su fuente que seguirán en contacto durante el camino para estar más informado en cada paso que da, pero muchas veces no es posible, en ocasiones por la precariedad, riesgo e irregularidad de las comunicaciones de los indocumentados en México y en otras porque la fuente, que puede estar en algún punto de su país de origen, de México o de Estados Unidos, deja de estar localizable. Si el contacto está en Estados Unidos, esta ruptura de la comunicación genera aún más zozobra en el migrante, puesto que muchas veces se trata de la persona 
que debe recibirla y ayudarla a su llegada a ese país.

Otro vínculo comunicativo indispensable se da entre miembros de una misma familia en el que uno decide iniciar primero el viaje $y$ reunirse con el otro en algún punto. Esto fue lo que hicieron Axel, de 14 años, y un hermano de 22. Axel partió solo de Honduras, cruzó Guatemala y se encontró con su hermano en el refugio de Tenosique. Durante su paso por Guatemala, Axel pidió dinero en la calle para poder conectarse a Internet en un cibercafé y hablar con su hermano por Facebook para recibir sus instrucciones. En el momento de la entrevista, ambos habían solicitado asilo en México por las amenazas sufridas por pandillas en Honduras pero no tenían intención de quedarse en el país. Su plan, como el de muchos otros migrantes, era conseguir documentos legales que les permitieran llegar de forma segura hasta la frontera estadounidense.

Los migrantes que se informaron con fuentes directas reconocen que, por muy completas que sean las instrucciones y la descripción del camino que reciben, la realidad supera siempre las instrucciones.

Mucha gente le dice a uno cómo es el camino pero mientras uno no lo experimente por sí mismo, no sabe... Yo sentía miedo al salir pero ni modo, tenía que hacerlo.

(Lilian. 26 años, El Salvador. Su hermana le aconsejaba y le mandaba dinero desde Estados Unidos pero llegó un momento en que perdió el contacto y tuvo que empezar a pedir limosna y a viajar en el tren junto a su esposo).

Lilian huyó con su familia por un temor fundado de persecución. Un pandillero que mató hace unos años a su hermano estaba a punto de salir de prisión y había jurado asesinar al resto de la familia. Sin embargo, Lilian no ha solicitado protección en México. Quiere llegar cuanto antes a Estados Unidos y empezar a mandar dinero a casa para el cuidado de sus hijos, de 7 y 9 años.

Una vez iniciado el camino, los migrantes tienen a su mano básicamente tres tipos de fuentes de información directas: otros indocumentados con los que se encuentran en la ruta, los activistas de los refugios y los habitantes de México con los que se cruzan en su camino. A la policía u otras autoridades tratan siempre de esquivarlas para evitar ser detenidos.

\section{Compañeros de viaje}

En general, los migrantes reciben la información de estas fuentes con cierta desconfianza, en mayor 
- menor grado, por tratarse de personas desconocidas. Los recelos son mayores entre el colectivo migrante. Es sabido que en la ruta hay centroamericanos que trabajan para el crimen organizado mexicano y se infiltran en grupos de migrantes para conseguir información para los asaltantes o secuestradores. De esta forma, les pueden avisar de por donde circulan los migrantes $\mathrm{y}$, si logran entrar en confianza con ellos, pueden saber qué víctima les puede proporcionar más beneficios. El dato más codiciado por los criminales es identificar qué migrante tiene familiares en Estados Unidos para secuestrarle y obtener el pago de un rescate. Esta situación también se da en los albergues, donde la posible presencia de infiltrados de la delincuencia es una preocupación constante.

\section{Tengo poca confianza para hablar en la casa. Algunas personas vienen sólo a escuchar con quién se comunica uno, si tiene dinero, cosas así. Es mejor ser reservado. \\ (Franklin. 24 años, Honduras. Huyó porque una pandilla quería reclutarlo. Al llegar a México fue atropellado junto a dos amigos con los que viajaba y uno de ellos murió. Le concedieron una visa huma- nitaria y se recuperaba de las lesiones en el refugio de Tenosique).}

Pese al peligro real de infiltración, la mayoría de los migrantes siente que viajar en grupo les conlleva más beneficios. Por un lado, se sienten menos expuestos a asaltos y secuestros que desplazándose solos y se generan vínculos de solidaridad y camaradería. Por el otro, pueden obtener información de migrantes con experiencia en este camino, que para ellos sigue siendo desconocido.

Siempre encuentras a otros migrantes que también quieren llegar a Estados Unidos y otros que han regresado de allí y que tienen la información más 'calentita', como dicen. Está mucho más complicado pasar a Estados Unidos ahora que hace 10 años.

(José Luis. Honduras, 42 años. Emigró por un problema familiar y trata de cruzar a Estados Unidos por tercera vez).

Habitantes de México

Muchos migrantes también desconfían de los lugareños, con quienes tienen que interactuar a diario en numerosas actividades, como comprar comida o pedir indicaciones. Temen que estas 
personas, al darse cuenta de viaje sin hablar con personas del que hablan con extranjeros indocumentados, les engañen para robarles o para entregarles a grupos criminales. El acento también puede resultar un problema a la hora de hacer trámites como comprar billetes de autobús. Algunos migrantes reconocen que han tratado de imitar el habla de los mexicanos para no ser reconocidos como extranjeros, por temor a que pudieran dar aviso a las autoridades. Sin embargo, ninguno de los migrantes entrevistados relató haber tenido un problema de ese tipo. Como resulta prácticamente imposible hacer este lugar, los migrantes recurren a su instinto para determinar si se pueden fiar de ellas. Si se trata de conseguir una información práctica, algunos hacen la misma pregunta a varios mexicanos para ver si las respuestas coinciden mientras que otros prefieren consultar a las personas cuya apariencia les parece "más humilde". Dos de los entrevistados reconocieron que en cada pueblo al que llegaban acudían a iglesias en busca no sólo de apoyo espiritual sino también de información segura y práctica.

Aquí no me fío de nadie. Ya sabemos que México es un país donde la mafia sale de un lado y de otro... Lo más confidencial es ir a las iglesias. Siempre preguntaba dónde había una cerca porque yo sé que un padre no me va a mentir.

(Jimmy. Honduras, 19 años. Huyó de un contexto de violencia y pobreza. En Celaya, Guanajuato, centro de México, sobrevivió a un asalto en el tren en el que murió uno de sus acompañantes).

\section{Defensores de migrantes}

De todos los informantes que encuentran los migrantes en su camino, los que más confianza les infunden son los activistas de las casas refugio, tanto los trabajadores como los voluntarios, que en ocasiones provienen de países europeos o latinoamericanos.
Les reconocen su compromiso de apoyo y defensa de los derechos humanos de los indocumentados $y$ el conocimiento que acumulan por su labor. Por encima de todos, en quienes más confían es en los sacerdotes que dirigen estas instituciones, como el padre fray Tomás González en Tenosique o el padre Pedro Pantoja en Saltillo. 
La mayoría de la gente llega sin ninguna información pero aquí (albergue de Tenosique) les explican cómo ir para arriba y les dan un mapa. Yo no sabía ni para dónde tomar pero estando en la casa he investigado bastante. Ahora sé que hay partes que son bastante peligrosas, que si viajas en el tren tienes que pagar una cuota (a criminales) y si no te bajan, que a muchas mujeres las violan... El fray platica con nosotros y nos dice por dónde está peligroso, por dónde lo están asaltando a uno, que si a unos 'chavos' que se fueron de aquí los secuestraron en tal parte.

(Jessica Yessenia. 23 años, Honduras. Madre de una niña de cuatro años que huyó tras ser víctima de un asalto y un intento de violación. Le han aceptado la solicitud de asilo en México).

Miles de migrantes son recibidos cada año con comida, ropa y alojamiento gratuito en las casas refugio de Tenosique y Saltillo, lleguen a la hora que lleguen. Además, les brindan información sobre los peligros de las rutas, les dan consejos prácticos, documentan los casos de violaciones a los derechos humanos y les asisten jurídicamente. En el exterior del refugio de Tenosique hay un módulo de la Cruz Roja mexicana en el que los migrantes que llegan pueden recibir primeros auxilios y hacer una llamada. Dentro de la casa hay un módulo compartido por la ONG Asylum Access y por ACNUR, que ofrecen charlas a los beneficiarios sobre el proceso de solicitud de asilo en México y asesoría jurídica, y otro de Médicos Sin Fronteras de atención psicológica. Estos módulos no se encuentran en el refugio de Saltillo pero el tipo de atención es similar.
Los trabajadores y voluntarios de las casas refugio llevan a cabo su labor en un entorno de alta inseguridad. En los últimos años han sufrido robos, intimidaciones y amenazas por grupos criminales. A pesar de que la labor de las casas refugio está protegida por la ley mexicana, sus trabajadores han sido también hostigados por las autoridades, que han llegado a detener a algunos de los defensores de migrantes más emblemáticos en México, como el padre Alejandro Solalinde.

\subsubsection{Fuentes indirectas}

Además de las fuentes directas, los migrantes tienen estos días la posibilidad de acceder a información disponible en Internet. Consultados al respecto, apenas seis entrevistados recordaban haber hecho búsquedas en la red antes de partir o durante el viaje. A pesar de que, como veremos 
más adelante, algunos migrantes emplearon Google Maps para guiarse durante su camino, ninguno de ellos se descargó o imprimió mapas de las rutas. Básicamente se trató de búsquedas generales en Google $y$ en Youtube, sin acceder a sitios electrónicos de organizaciones humanitarias $u$ otras de apoyo a los migrantes.

En Youtube encontré bastante información útil sobre cómo viajar en los trenes, cómo bajar, qué es lo que tiene que hacer uno, cómo tiene que andar, todo eso.

(José. 20 años, Honduras).

Más allá de sus búsquedas en Youtube, ninguno recuerda las webs a las que accedió. Salvo alguna excepción, como José, los migrantes no encontraron el tipo de información y consejos prácticos que necesitaban.

En Youtube busqué vídeos de cómo llegar a Estados Unidos
cruzando México y la mayoría de los que encontré eran nega-
tivos, desalentaban la salida, decían que no lo intentáramos...
Los que habían hecho esos vídeos eran la mayoría americanos,
personas que no querían que saliera la gente para allá. Era
como decirnos 'quédate, no te vayas, no te queremos aquí. No
encontré información útil sobre el viaje, una ruta para cruzar,
tener una idea más o menos clara de cómo estaba la situación.

(Francisco. 38 años, Honduras).

\subsection{Necesidades de comunicación}

Además de la necesidad de información útil y oportuna, los migrantes también requieren poder comunicarse con sus seres queridos o con personas que les pueden asistir en su viaje. En general, los centroamericanos consideran que su comunicación en México es insuficiente por la falta de recursos propios y de ayuda externa y porque el uso de teléfonos o redes sociales se considera en esta ruta más un riesgo que un beneficio. La mayoría de los migrantes valoran la comunicación como una prioridad en la que muchas veces deben invertir una parte importante de sus escasos recursos, renunciando a otras necesidades. 
Si no te puedes comunicar es como estar muerto en vida. Sientes que no llevas un apoyo, sientes aquel vacío. Lo que más quieres es darle esa confidencia a tus familiares, de cómo vas, a dónde vas a ir. Es lo más importante, más que comer bien, dormir seguro. Si no, te sientes triste, agobiado. No tienes a nadie, te sabes solo con personas que ni tan sólo conoces y no sabes a dónde te llevan (...) Yo prefería hablar con la familia y no comer.

(Jimmy. Honduras, 19 años).

Al igual que Jimmy, otros centroamericanos requieren de comunicación con sus familias por su salud emocional. Los responsables de la atención psicológica del refugio de Saltillo señalan que el hecho de contactar con sus casas por teléfono, aunque sea brevemente, reduce sensiblemente los niveles de estrés de los migrantes.

\begin{abstract}
Es lo más importante que puede haber, tener comunicación con la mamá, con los hijos. Yo a veces me siento bastante triste y deseo sólo dormir y dormir. Cuando pasa el tiempo y no hablo con mi hija y con mi mamá, deben de estar pensando qué estoy haciendo, si estoy bien, si estoy mal.
\end{abstract}

(Jessica Yessenia. 23 años, Honduras).

\subsubsection{Comunicación telefónica}

El principal medio de comunicación de los migrantes con sus países sigue siendo el teléfono. Prácticamente, todos los entrevistados lograron comunicarse por esta vía en algún punto del viaje, como mínimo en una ocasión. En el trabajo de campo se percibió una gran diferencia en el número de personas que contaban con un teléfono celular en el albergue de Tenosique respecto al de Saltillo. En el primero, situado en el sur de México, 11 entrevistados tenían un teléfono y 8 no, mientras que en el segundo, en el norte, eran 5 los que tenían y 16 no. Muchos de estos últimos habían llegado a México con un celular o adquirieron uno en el país pero se lo robaron o decidieron abandonarlo o venderlo por su seguridad.

De los que no contaban con un teléfono en Tenosique, 5 querían conseguir uno pero no habían podido por falta de recursos. Sólo un migrante había decidido viajar sin celular, aunque en general todos eran conscientes de los riesgos que conlleva, los cuales serán analizados en profundidad en el último apartado. 
Me dijeron que en este camino asaltaban, robaban cualquier cosa, te dejaban sin nada. Me obligué a dejar el teléfono en casa. En Honduras cuesta mucho tener un buen teléfono.

(José. 24 años, Honduras. Huyó por amenazas de la pandilla Barrio 18, que extorsionaba el negocio de su hermano. En el momento de la entrevista llevaba 20 días sin poder comunicarse con su casa).

En el norte de México, de los 16 entrevistados que no tenían teléfono, únicamente 4 estaban interesados en adquirir uno, pero sólo uno de ellos aseguraba que lo llevaría consigo en su camino hacia la frontera. El resto lo quería sólo para el tiempo que estuvieran en el albergue gestionando sus trámites de refugio o trabajando para reunir fondos para el resto del viaje. Aquellos que compraron su celular en México -algunos a compañeros migrantes $y$ otros en establecimientos formalesinvirtieron entre 750 y 900 pesos mexicanos (36 y 44 dólares en ese momento).

Después, la mayoría dijo haber adquirido una tarjeta telefónica mexicana de la compañía Telcel que, además de ofrecer acceso a Internet, permite hacer llamadas ilimitadas a territorio mexicano y de Estados Unidos. El coste del paquete varía dependiendo del número de días por el que se contrate, pero el más adquirido parece ser el que da servicio por una semana por 50 pesos (2,4 dólares). Algunos migrantes tienen familiares 0 conocidos establecidos en Estados Unidos o México que cargan saldo en la tarjeta por ellos. Otros calculan haber gastado cantidades superiores a los 300 pesos (9,7 dólares) en recargas, un gasto importante y a veces inasumible para los migrantes, que en ocasiones tienen que pedir ayuda en la calle para afrontarlo.

Siento que es muy duro comprar un teléfono aquí porque nosotros no podemos trabajar legalmente, tenemos que cuidarnos siempre de Migración. Y yo no tengo quien me ayude allí arriba.

(Henry. 19 años, Honduras. Miembro de la comunidad LGBT que huyó por amenazas de delincuentes y viaja solo hacia Estados Unidos).

Entre los migrantes también hay quien decide invertir sus recursos en otras cosas: 
La prioridad del dinero que me han mandado es ropa y comida. El teléfono no ha sido mi prioridad porque puedo comprar una tarjeta y llamar de los teléfonos públicos.

(José Luis. Honduras, 42 años).

El uso principal de los teléfonos celulares en este camino son las llamadas, aunque también se utilizan para navegar por Internet, comunicarse por redes sociales, escuchar música, enviar y recibir fotos y mirar la hora. La frecuencia con la que realizan llamadas, ya sea con sus celulares o con los teléfonos de refugios, varía mucho dependiendo de las circunstancias y los recursos. Como se verá más adelante, pocos migrantes cargan teléfonos cuando van a viajar en tren y algunos refugios, como el de Saltillo, no permiten usar celulares, todo lo cual contribuye a restringir las llamadas.
Resulta difícil establecer un promedio de la frecuencia con la que los migrantes se comunican por teléfono. Cuando se encuentran en refugios, depende de si disponen de un teléfono celular y de si sus allegados tienen recursos para llamarles. En la ruta, la comunicación se vuelve mucho más esporádica y la mayoría reconoce haber llegado a estar una, dos o tres semanas sin contacto con sus padres, hijos y otros seres queridos.

Tras ser operado por el atropello que sufrió, Franklin estuvo tres semanas hospitalizado sin poder comunicarse con su familia para explicarles lo sucedido.

\begin{abstract}
Nadie sabía de mí. En el hospital me ofrecieron un teléfono para llamar a mi casa pero yo no me sabía el número. Mi amigo que falleció en el atropello llevaba los números de teléfono de todos en un papel escondido en su pantalón. Al final les pedí que me dejaran conectarme a Facebook y que me tomaran una foto con el pie enyesado para subirla. Todo el mundo empezó a preguntarme qué me pasó.
\end{abstract}

(Franklin. 24 años, Honduras).

Para los migrantes que ingresan a México por el estado de Tabasco, el refugio de Tenosique suele ser el primer punto donde pueden hacer una llamada a sus familias. Antes de llegar han superado el tránsito por Guatemala,que suele llevarles únicamente uno o dos días. Prácticamente, en Guatemala ninguno pudo comunicarse, ya fuera porque no tenían 
recursos o querían reservarlos o porque no lograron conectarse con sus celulares por falta de una tarjeta telefónica del país. Según relató un entrevistado, las tarjetas telefónicas de Honduras pueden ser activadas en Guatemala siempre que se avise previamente del viaje a la compañía. Otro migrante pudo utilizar Google Maps para guiarse por Guatemala, una herramienta que también es empleada en la ruta mexicana. Una vez en Tenosique, prácticamente todos los migrantes utilizan la llamada telefónica que ofrece la Cruz Roja mexicana con la financiación del Comité Internacional de la Cruz Roja.

La media de Llamadas ofrecidas al día es de unas 30 , según sus responsables. ${ }^{3}$ El servicio es anónimo pero no totalmente confidencial. Los miembros de la Cruz Roja no preguntan el nombre a los migrantes pero uno de ellos permanece junto al usuario durante la llamada y escucha por tanto parte de la conversación. La recomendación que se les indica a los migrantes es que aprovechen los escasos tres minutos que puede durar la conversación para que den a su interlocutor el máximo de información posible sobre su estado de salud, ubicación y planes. Esta unidad móvil de la Cruz Roja se desplaza también regularmente a algunos puntos de la vía de tren y otros puntos de tránsito de migrantes para ofrecer el servicio. De igual forma, la institución tiene unidades en otros puntos de la ruta migratoria de México como Arriaga (Chiapas, sureste), Ciudad Serdán (Puebla, centro) y Tijuana (Baja California, noroeste).

En el interior del refugio de Tenosique, los beneficiarios pueden usar sus celulares y recibir llamadas al teléfono del albergue. Aquellos que tienen saldo en sus celulares no tienen problemas para comunicarse las veces que quieran con personas emplazadas en México o en Estados Unidos. La estampa habitual en este albergue es la de numerosos migrantes sentados 0 acostados utilizando su celular para hacer llamadas o chatear por redes sociales.

Hablo por teléfono todos los días. Hago como 30 llamadas al día a amigos en Estados Unidos.

(Francisco. 38 años, Honduras).

Las personas que no cuentan con un teléfono en ocasiones piden uno prestado tanto para hacer llamadas como para recibir claves de transferencias de dinero a través de mensajes
SMS o ingresado a Facebook. Como se verá más adelante, esta opción puede generar importantes problemas de seguridad tanto para quien 
pide el teléfono como para quien lo presta.

Los entrevistados relatan que a medida que avanzan en su ruta por México van dejando o perdiendo los celulares y llamando básicamente a través de los teléfonos de los refugios u otros públicos. En el albergue de Saltillo, donde está prohibido el uso de celulares, los usuarios se comunican básicamente por los teléfonos instalados en la casa. Este tipo de comunicación conlleva varios problemas: el primero es que se necesitan recursos económicos para comprar las tarjetas que hacen funcionar los teléfonos. Para ello, algunos migrantes destinan una parte del dinero que reciben por cada día que trabajan fuera del refugio. Según explican, resulta mucho más barato llamar desde México a Centroamérica que a la inversa. Sin embargo, los migrantes se quejan del funcionamiento de estos teléfonos. Por un lado, les parece que el tiempo de llamada que ofrece la tarjeta es insuficiente para su precio, más teniendo en cuenta las dificultades que existen también en sus comunidades de origen y, por el otro lado, se dan muchos cortes de comunicación.

\begin{abstract}
Las tarjetas de 30 pesos (1.5 dólares) duran seis minutos y seis minutos no me alcanzan para todo lo que yo tengo que decir. En lo que llamo a mi prima y ella avisa a mi madre de que la estoy llamando, ahí se van los seis minutos.
\end{abstract}

(Lilian. 26 años, El Salvador).

Los teléfonos se cortan mucho. Tal vez de cinco llamadas, una se corta ya sea por una interrupción aquí o allá.

(Guillermo. 53 años, Guatemala. Maestro jubilado. Salió de su país porque su pensión no le alcanzaba para vivir. Llevaba siete meses en el refugio de Saltillo donde se ocupa de atender las llamadas que se reciben).

Antes de llegar al albergue de Saltillo, Guillermo estuvo siete meses en la estación migratoria de Acayucan (Veracruz, este), donde extranjeros indocumentados son retenidos a la espera de ser deportados o de que se dé respuesta a las solicitudes de estancia en México. Según su experiencia, las autoridades no dan facilidades para la comunicación dentro de esas instalaciones. Guillermo apenas pudo hacer llamadas una o dos veces por mes, de cinco minutos cada una, teniendo que sufragar las tarjetas telefónicas por su cuenta. 
Con todo, hay una gran diversidad de personas y situaciones dentro del flujo migratorio centroamericano. Hay quien prefiere no comunicarse para no exponer su seguridad, quien no tiene nadie a quien contactar o quien cree que lo mejor es no llamar a casa para no crear una falsa expectativa de que está cerca de conseguir su objetivo.

A mi familia le dije que les iba a llamar cuando estuviera en Estados Unidos. Si les llamo antes tendrían la expectativa de decir "me va a mandar dinero". Más que todo es la esposa de uno. Yo trato de que tenga paciencia porque ya voy a llegar.

(Antonio. 49 años, Guatemala. Vivió 25 años en Estados Unidos hasta que fue deportado en 2011. Ahora quiere volver y ahorrar para que se le puedan unir su esposa e hijos).

\subsubsection{Comunicación por redes sociales}

Además de los teléfonos, los migrantes centroamericanos también usan cada vez más las redes sociales en su camino por México. La más popular con diferencia es Facebook, empleada por 22 de los 40 entrevistados. Otros dos migrantes también intentaron acceder a sus cuentas en México pero no lo lograron por problemas con la contraseña. Entre quienes no se han conectado a Facebook, tres migrantes lo evitaron por temor a que les generara un problema de seguridad y otra más decidió directamente cerrar su cuenta antes de abandonar su casa en Guatemala.

El principal propósito de la comunicación por Facebook que señalan los migrantes es poder comunicarse con familiares y otros conocidos que están en sus países de origen o en Estados Unidos. Esta red social también es utilizada para contactar con personas que creen que les pueden ayudar a superar los obstáculos del camino, para recibir claves para retirar transferencias de dinero y para leer noticias y ver qué dicen sus amigos.

Son mejores las redes sociales para comunicarse porque si llevas números de teléfono, cosas así, son más propensas a que cuando te secuestren, te extorsionen. Mientras que una red social, puedes ir a un lugar donde hay Internet, conectarse y sólo eso.

(Franklin. 24 años, Honduras). 
Las comunicaciones en Facebook se llevan a cabo principalmente en chats individuales. Ninguno de los entrevistados dijo estar integrado en algún grupo de migrantes en
Facebook y, de hecho, apenas dos de ellos dijeron que habían agregado en Facebook a alguna persona que conocieron en México.

Tengo amigos que he encontrado en el camino y los tengo en el "Face". Hay algunos que me cuentan que están de vuelta en Honduras, o que les ha agarrado Migración, y otros que ya están en Estados Unidos. Son como unos 30.

(Omar. 16 años, El Salvador).

La segunda red social más que pueden evitar que alguien popular entre los centroamericanos migrantes parece ser WhatsApp. vea lo que escriben, mientras que Nueve de los entrevistados la han usado durante su viaje. Quienes usan Facebook y WhatsApp consideran que cuando acceden a Facebook, tanto en los refugios como en cibercafés, temen que alguien pueda observar la pantalla.

esta última es más segura puesto

Nunca he ido a la sala de computadores de la casa (de Tenosique). Se llena bastante y lo están viendo a uno, no hay mucha privacidad.

(Víctor. 32 años, El Salvador).

Sólo uno de los migrantes entrevistados tenía la práctica de enviar a

alguien por WhatsApp su ubicación para que se supiera dónde estaba.

Cada vez que me muevo mando la ubicación por WhatsApp de a dónde me moví y también por escrito para que se sepa exactamente dónde estoy.

(Francisco. 38 años, Honduras).

Cinco de los entrevistados también habían utilizado en sus teléfonos el servicio de mensajería Messenger, que suele estar ligado a las cuentas de Facebook. Además de estos servicios de chat, varios de los migrantes también se comunicaron con sus teléfonos a través de videollamadas vía WhatsApp, Messenger e Imo. 
Como se mencionaba antes, guiarse por caminos apartados y algunos migrantes están también que también les ha ahorrado la utilizando Google Maps. Cuatro de exposición de pedir indicaciones a los entrevistados señalaron que personas de la zona. les ha sido de mucha utilidad para

Nos conectábamos al Wifi de las terminales de bus y, para no preguntar, buscábamos en Google Maps la ruta más fácil.

Omar (17 años, El Salvador).

En cuanto a las necesidades de conectividad, la mayoría de los migrantes señala que nunca tuvo problema para cargar la batería de sus teléfonos. Lo podían hacer en los refugios de migrantes $o$ en tiendas que encontraban en el camino o en hoteles o moteles, si pernoctaban en ellos. Si pensaban que podían estar un tiempo largo sin acceso a electricidad, trataban de llevar el teléfono apagado y sólo encenderlo cuando necesitaban usarlo. Más problemas detectaron para conectarse a las redes telefónicas o de Internet en determinados pueblos o caminos que tomaban en su ruta.

La necesidad de comunicación también llevó a los migrantes a aprender a usar estas aplicaciones tecnológicas o a perfeccionar su conocimiento. Franklin, por ejemplo, comenzó a utilizar el Messenger en México; Júnior y Omar se consideran ya expertos en Google Maps, mientras que Víctor, un salvadoreño de 32 años, abrió una cuenta de Facebook por primera vez en México.
No todos los migrantes, sin embargo, iniciaron su viaje con conocimientos tecnológicos. Personas provenientes tanto de zonas rurales como urbanas no tenían Internet en sus casas y alguno ni tan sólo teléfono.

\subsection{Riesgos}

Este apartado se enfoca en los riesgos asociados a la comunicación en el contexto migratorio en México, tanto del uso de los celulares como de los teléfonos públicos y de las redes sociales.

\section{Celulares}

La principal amenaza que perciben los migrantes en este ámbito está relacionada con viajar con teléfonos celulares. Para ellos, el mayor objetivo de los grupos criminales mexicanos es capturar a indocumentados que tengan a alguien que responda por ellos en Estados Unidos y poder forzarles a proporcionar el contacto de esa persona. 
Si el migrante guarda el número de esa persona en Estados Unidos, o de familiares en su país de origen, en su teléfono celular entonces estaría facilitando el objetivo de los criminales. $Y$ aunque el migrante no conozca a nadie en Estados Unidos, el simple hecho de portar un teléfono puede llevar a los criminales a sospechar que así es y motivar un secuestro que, en el peor de los casos, puede derivar en tortura y asesinato.

\begin{abstract}
El teléfono es muy importante, la verdad, pero en el tren es un arma de doble filo. El problema es que nadie anda con teléfono en el tren y si llegan los asaltantes para ellos es seguro que el que lleva teléfono tiene familiares. Ahí lo agarran y se lo llevan, es una señal clara. Piensan, "isi la gente anda en el tren porque no tiene para el bus, entonces para qué anda con teléfono?"

Francisco (38 años, Honduras).
\end{abstract}

Después de salir del refugio de Palenque había que rodear un operativo caminando y ahí estaban los pandilleros pidiendo números de teléfono. Lo revisan a uno y el teléfono se lo quitan. Ahí le quitan todo a uno. Están todos fumando drogas y lo rodean a uno, revisan si llevas números de teléfono o si vienes llamando a alguien.

Antonio (37 años, Honduras).

Otro de los motivos más puede que le exijan a esa persona recurrentes por el que los migrantes que les abone la llamada "cuota" por no quieren viajar por México con permitirle cruzar migrantes por el un celular es el riesgo de que les confundan con un "coyote", tanto si les interceptan grupos criminales como las autoridades migratorias. Cuando sucede un asalto de delincuentes a un grupo de migrantes puede ocurrir, cuentan, que los criminales deduzcan que aquel que lleva un celular es quien guía a todos hacia el norte. En ese caso, los criminales territorio que ellos controlan. Este ha sido el modo de operación del cártel mexicano Los Zetas en los últimos años. Cada "coyote" que quisiera utilizar rutas por zonas de influencia de este grupo narcotraficante debía pagarles una cantidad determinada por cada migrante, que se estima en unos 200 dólares.

No es conveniente llevar teléfono. Si así como soy, sin nada, la gente sospecha que yo soy alguien de esas personas (coyote), 
no digamos trayendo un teléfono. Si alguien camina con el teléfono, sucio, con mochila, ése es el coyote. Hay mucha gente que va observando.

Octavio (30 años, Guatemala).

Los migrantes temen ser caso de ser interceptados por las acusados de traficantes de personas por llevar un celular también en el autoridades migratorias mexicanas.

Si voy en un autobús solo pero vienen otros 10 ilegales $y$ Migración me agarra por desgracia a mí solo con un teléfono, ¿qué van a pensar? "Tú los traes, tú traes el teléfono, tú eres el guía" (...) Y a quién van a creer más es a ellos porque son autoridad.

José (31 años, Honduras).

Además de la posibilidad de en la ruta se expone también a ser confusiones fatales como éstas, la víctima de robo. persona que carga con un celular

Aquí cuando le ven a uno con un teléfono, se lo quieren robar. Si es un "Smartphone", aunque sea de los baratos, todo el mundo le anda poniendo el ojo (...) Y aquí adentro (refugio de Tenosique) es de que alguien lo deja cargando y otro lo agarra. En lo que llevo aquí han sido cuatro los que se han "perdido". Yo en la noche me lo meto en mi bóxer.

Francisco (38 años, Honduras).

Pedir prestado un teléfono o que alguien te lo preste para hacer una llamada o mandar un mensaje también puede causar problemas. Por los testimonios recogidos, éstas parecen ser prácticas habituales en la ruta. Algunos refugios, como el de Tenosique, recomiendan directamente no pedir ni prestar el teléfono pero se dan casos. El riesgo de usar el teléfono de otro migrante es que el número del familiar o conocido al que se llama puede quedar grabado en el aparato y ser usado para fines extorsivos. En este caso, existe la posibilidad de tomar la precaución de borrar el número al que se llama antes de devolver el teléfono, pero no siempre se hace. En el caso de prestar el teléfono, es 
el propio número del migrante el que queda marcado en el aparato al que se llama.

Nunca he pedido una llamada. Uno en este camino desconfía. ¿Qué tal que le hacen una extorsión a mi familia por el número telefónico?

Alexander (15 años, Honduras).

El caso de Franklin, el joven le pedían usar su teléfono para hondureño atropellado que se recuhacer una llamada o para recibir peraba en el refugio de Tenosique, es también ilustrativo de la claves para recoger transferencias demanda de celulares que existe en este camino. El muchacho cuenta que cada día numerosas personas bancarias. A Franklin estas personas le agradecían el gesto después con regalos hasta que esta práctica le comenzó a generar problemas.

Le presté el teléfono a una persona conocida aquí. Quería decirle a su familia que llegaría a Ciudad de México al día siguiente. En la noche se fue de la casa y a los dos días me empezó a llamar la familia preguntando por él. "Han pasado dos días y no ha venido, localizamelo por favor", me decían. Ellos tenían mi número registrado y era el único al que podían preguntar por él. Yo les decía que estaba en una camilla y no podía ir a buscarlo pero me insistían y me insistían. Estuvieron una semana llamando hasta que por fin el hombre llegó allá y me pidieron disculpas. Yo tenía miedo de que me denunciaran (...) Llegaba a recibir 50 llamadas preguntando por gente. Al final empecé a negarme a dejarlo diciéndoles que la casa lo prohíbe.

Franklin (24 años, Honduras).

Franklin ya sabía lo que era estar en peligro por un celular. Los grupos criminales de Centroamérica los tienen como una fuente de información importante. Los pandilleros que querían reclutar a Franklin en Honduras utilizaron el aparato para estar seguros de que el joven no pertenecía ya a una banda rival. 
Los mismos pandilleros me quitaron mi teléfono en Honduras y me dijeron que me lo iban a tener en investigación para ver si pertenecía a una pandilla. Miran las llamadas, los mensajes en Facebook, todo para ver qué le escribes a los amigos, quién te escribe. Te exigen la contraseña o muchas veces el Facebook ya está abierto. En Honduras tienes que tener mucho cuidado de lo que haces con tu teléfono, no bromear con amigos de ciertos temas.

Franklin (24 años, Honduras).

David, también hondureño, las trampas que su grupo criminal vivió estas experiencias en primera tendía en Tegucigalpa para extorpersona pero del otro lado; como sionar a través de los teléfonos, uno de los pandilleros que extor- empleando sus redes de corrupción: sionaban. En la entrevista recuerda

Yo me encargaba de subir a los buses y al que veía bien vestido le decía: “disculpe, me deja hacer una llamada?” Entonces yo llamaba a mi jefe o me llamaba a mí para que ese número quedara registrado, y me bajaba. Esa era la misión. Luego mis compañeros llamaban a esa persona y le decían "preséntate, necesitamos tanto dinero". Y si no lo hacía, mandábamos su número a la central de la policía y ya sabíamos quién era y dónde vivía y lo comenzábamos a vigilar. (...) Los jefes tienen "conectes" en la policía. Por eso se llama crimen organizado. Nunca hay que confiar en nadie.

David (30 años, Honduras).

\section{Teléfonos públicos}

Una sospecha similar a la de los celulares ajenos se da en el caso de los teléfonos públicos, aunque con menor intensidad. En general, los migrantes utilizan las cabinas instaladas en los refugios siempre que pueden. Cada vez que en las casas se grita el nombre de algún usuario para que acuda a responder una llamada, éste aparece veloz y sonriente. Una Llamada puede significar escuchar una voz querida, familiar, un mensaje de ánimo, de esperanza o el esperado número para recoger una pequeña transferencia de dinero que le ayude a seguir el camino. Sin embargo, algunas personas desconfían de la privacidad de esta comunicación y prefieren, si tienen la oportunidad, utilizar sus 
propios teléfonos aunque deban afrontar un coste. De hecho, varios migrantes entrevistados relataron casos de extorsión sufridos por sus familias después de utilizar los teléfonos de los refugios en varios puntos de México. Nathaly, una joven transgénero, explica que en una ocasión utilizó un teléfono del albergue de Saltillo para llamar a su casa en Honduras. Días después volvió a comunicarse y su madre le dijo que en ese lapso había recibido llamadas diciendo que tenían retenida a su hija en Estados Unidos y que sólo la liberarían si mandaba una cierta cantidad de dólares.

Yo le dije a mi madre: "usted no le crea nada a nadie. Yo estoy muy bien, estoy en una casa de migrantes y estoy tranquila". A muchas personas ya les han hecho esto. No sé si es de aquí dentro (del refugio) o de fuera que escanean las llamadas pero eso a veces nos da miedo.

Nathaly (21 años, Honduras).

\section{Redes sociales}

No hay consenso entre los migrantes sobre si es más seguro comunicarse por teléfono o por redes sociales. Para muchos, la comunicación digital resulta más adecuada en este contexto de alta inseguridad puesto que no requiere transportar un celular, con todos los problemas que se han explicado anteriormente, ni aprenderse de memoria largos números telefónicos.
Sin embargo, también se han detectado riesgos graves de seguridad por el uso de redes sociales como Facebook que se agudizan cuando se trata de migrantes que han tenido que huir de su país por amenazas y se siguen sintiendo perseguidos por los mismos actores pese a estar en el extranjero. Este temor es más palpable en aquellos que se sienten perseguidos por integrantes de grupos criminales que se han expandido también a México, como las maras Barrio 18 y Salvatrucha.

En Facebook tú publicas cosas y ahí sale para poner la ubicación donde te encuentras, o te sale, y ellos pueden decir "ah, éste anda por tal lado". Entonces, si tienes problemas ahí te van a ir a encontrar. $O$ muchas veces pones fotos de tu familia y les pueden agarrar (...) Hay muchas personas huyendo, que las andan buscando para matarlos.

Junior (23 años, El Salvador). 
No quiero revisar Facebook porque pienso que al ingresar yo a Internet alguien pueda saber dónde estoy.

Telma (31 años, Guatemala).

Otro temor relacionado con el uso o cuando el celular es extraviado o de redes sociales en esta ruta es que robado, y otra persona pueda acceder no se cierren completamente, ya sea a la información personal.

cuando se usan en una computadora

No uso redes sociales por mi familia, sobre todo. Mi hermana está en Estados Unidos y le pueden pedir algo, que mande dinero o cosas así. Y el Facebook siempre puede quedar abierto.

Franklin (24 años, Honduras).

\subsection{Medidas de protección}

Apenas cinco entrevistados aseguran haber planeado, antes de iniciar el camino, una estrategia de comunicación que favoreciera su protección, ya fuera que después lograran llevarla a la práctica o no. La idea inicial más repetida fue la de intentar comunicarse cuándo y dónde fuera posible. Pero algunos sí dedicaron tiempo y esfuerzo a valorar cada determinado contexto y a coordinarse con sus familiares. Para ellos resultaba de vital importancia que sus allegados tuvieran la ubicación lo más exacta posible de dónde estaban cada día, para así poder iniciar una búsqueda más efectiva en caso de pérdida de contacto.

Lo hablé con un hermano mío que pasó por acá. Le dije que todos los días me tiene que marcar a las seis y le digo dónde estoy y dónde me voy a mover. Y que si no contesto, es por algo.

Francisco (38 años, Honduras).

Mi hermano me dijo que siempre le avisara de dónde estaba porque si no mi familia se empieza a preocupar. Mi papá se perdió en México hace ocho años. Él también iba para Estados Unidos y una vez llamó, nada más.

Wendy (27 años, Honduras). 
Algunos migrantes también han establecido códigos para que su familia los reconozca cuando hablan por teléfono. De esta forma evitan que alguien pueda suplantar la voz del migrante, aprovechándose del mal sonido, interrupciones o la credulidad del interlocutor, y logre extorsionar a su familia haciéndola creer que tiene al migrante secuestrado o que le ha ocurrido algo y deben enviar dinero.

\begin{abstract}
Por si alguien quiere hacerse pasar por mí, le dije a mi familia que siempre que les hable les voy a dar un número. Hasta que no escuchen el número no deben creer que soy yo. Les digo, por ejemplo, "soy el seis", y si alguien les llama y no les dice ese número, entonces no soy yo.
\end{abstract}

José (31 años, Honduras).

Warner, de Guatemala, también reconoce que tiene un código compartido con su familia para comunicarse en confianza y es el de hablarles en su idioma indígena natal. De esta forma, aunque alguien escuche su conversación en el refugio o en otro punto de México, difícilmente va a entender el contenido del diálogo. De todas maneras, Warner atravesó por una experiencia amarga en México que le Llevó a relativizar la utilidad última de este tipo de medidas de seguridad. El joven viajaba en un tren de carga cuando los maquinistas detuvieron la marcha y se subió un grupo de miembros de Los Zetas. Warner cuenta que los secuestradores trataron de atrapar a su hermana pero que forcejeó con ellos y ella pudo huir con su cuñado. Warner fue capturado y llevado a una casa donde fue torturado para que diera el número de teléfono de su casa para exigir rescate por él. El joven asegura que, por mucha precaución que se tome con los números, si los secuestradores te atrapan tienes que darles la información que piden "o si no a uno lo matan".

Esta posición no es totalmente compartida entre el colectivo. Otros migrantes están convencidos de que si los secuestradores no les encuentran un teléfono podrían convencerles de que no tienen a nadie que responda por ellos y evitar la extorsión a sus familiares.

Si te encuentran un teléfono y hablan a una persona en Estados Unidos y ésta no les manda dinero, entonces te matan. Pero si uno no trae teléfono y le preguntan "itiene familia?" y uno se centra en que no y que no, ellos no tienen de dónde agarrar.

Lilian (26 años, El Salvador). 
$\mathrm{Si}$ se observa por tipo de de ser interceptados por el crimen transporte, los migrantes coinciden organizado. Algunos se arriesgan a en que se debe evitar llevar teléfono portar el teléfono en el tren pero en el tren. En el caso del autobús, tomando ciertas precauciones, como creen que depende del trayecto. descargar todas las aplicaciones Ven más seguro viajar en autobús o desmontarlo para que no pueda por el sur o centro de México que sonar y para que nadie encuentre por el norte. Cuanto más cerca de la todas las piezas juntas.

frontera, aseguran, más posibilidad

Yo le quito la batería y me la guardo en un lado y el chip en los zapatos y los números en la cabeza, uno no sabe qué puede suceder.

José (31 años, Honduras).

Mi esposo lleva el teléfono pero sin chip. El chip lo guardo yo $y$ en el teléfono no queda nada. En el momento que alguien se suba al tren, tiramos el teléfono y el chip (...) Usábamos el teléfono muy discretamente porque en el camino viene gente buena y gente mala. Hay que tener bastante precaución.

Lilian (26 años, El Salvador).

Otros necesitan una mayor y tratan de hacer desaparecer el certidumbre para sentirse seguros teléfono por completo.

No lo voy a tirar entero porque hay gente muy astuta que aunque haya borrado los números los puede recuperar. Entonces mejor lo quiebro y lo entierro en la tierra y ya.

José (31 años, Honduras).

A fin de cuentas, el elemento coinciden todos los migrantes es la básico de protección en el que discreción.

No llevábamos números de teléfono, no llevábamos dinero, no llevábamos vestuario que llamara la atención y cosas así. Nos pusimos una ropa encima de otra y nos vinimos sin mochila para que no pensaran que somos migrantes.

Franklin (24 años, Honduras). 


\section{Conclusiones}

Esta investigación muestra que existen oportunidades para ayudar a que los migrantes centroamericanos en México estén más informados y comunicados. La tarea es desafiante. De la gravedad de los testimonios se desprende que los medios con los que cuentan son muy precarios y los riegos que afrontan enormes. Todo ello en un marco de desconfianza extrema hacia las personas que se encuentran en su camino, hacia las autoridades y los propios compañeros de viaje, sean de su misma nacionalidad - distinta. La violencia desatada en México en la última década ha puesto a los migrantes en el punto de mira de los grupos criminales. Y no se avista voluntad política para combatir a estos grupos ni para ofrecer protección a los migrantes, muchos de los cuales deberían recibir el estatuto de refugiado como defiende ACNUR. Ante esta situación, sería conveniente que la acción humanitaria actúe con un enfoque integral ante el fenómeno y, como ha pedido la Federación Internacional de la Cruz Roja, establezca como una prioridad facilitar el acceso de los migrantes a información y comunicación confiable.

La investigación indica que la gran mayoría de los migrantes inicia el viaje extremadamente desinformados sobre elementos vitales como por dónde va a viajar, en qué transportes, con qué recursos y qué obstáculos y riesgos se va a topar en su camino. Aquellos que ya hicieron este viaje unos años atrás reconocen que las circunstancias han cambiado y se han endurecido. Los que parten con el único bagaje de la información que les suministró un familiar o un conocido se dan cuenta de que prácticamente nada es como habían imaginado. $Y$ aquellos que, cada vez en mayor número, tienen que huir de sus países repentinamente por persecución o amenazas reconocen que jamás se habían planteado emigrar. Estas personas no cuentan apenas con tiempo para informarse sobre el viaje y coordinar con su familia una estrategia de comunicación segura durante la ruta. Es común también que se acuerde mantener el contacto por teléfono o por Internet con alguna persona que conozca el camino y pueda dar recomendaciones, aunque esa comunicación después es muy difícil de mantener por las condiciones que se encuentran en México. Por tanto, las fuentes de información a las que acaba recurriendo la mayoría son aquellos desconocidos que encuentran en su camino y que les infunden más confianza, ya sean otros migrantes, activistas de los refugios, sacerdotes o lugareños. Se trata, por tanto, de fuentes de información con niveles insuficientes de calidad, cantidad y confianza. El ejemplo más dramático de ello son 
los migrantes que aseguran que de haber sabido realmente cómo era la ruta migratoria en México no hubieran comenzado el camino.

Por otro lado, se comienza a observar un incipiente uso de medios digitales para la búsqueda de información práctica para afrontar este camino. Este hecho se deriva del avance de Internet y de los conocimientos tecnológicos en sus países, así como de la ampliación del perfil de los potenciales migrantes, o en su caso, refugiados. Entre los entrevistados hubo personas que nunca han usado una computadora y otras con formación universitaria, incluido un estudiante de Informática. Según los entrevistados, en las búsquedas por Internet parece que se privilegia la información audiovisual más que textual, ya que la mayoría de búsquedas fueron en el portal Youtube. Ninguno recuerda tampoco haber descargado mapas para ir decidiendo la ruta a seguir. Los entrevistados apenas pueden mencionar otros sitios electrónicos consulados y, en cualquier caso, sus búsquedas en general no fueron satisfactorias.

Según lo expresado en las entrevistas, las principales necesidades de información de los migrantes son datos confiables sobre las zonas de mayor inseguridad por presencia de grupos armados; la ubicación de los retenes policiales; el coste de los sobornos que deberán pagar para poder seguir avanzando; las características de cada lugar que atravesarán, especialmente los que recorrerán caminando, los requisitos para solicitar protección en México y, si deciden pedirla, cómo avanza el trámite. En las entrevistas también se detectó cierta confusión en el conocimiento que tienen los migrantes sobre sus derechos en México, llegando en algunas ocasiones a naturalizarse el miedo a la criminalidad y a las autoridades. Las casas refugio tratan de proporcionar parte de esta información y de colaborar en los procesos de solicitud de asilo o visa humanitaria, pero sus recursos humanos y materiales parecen insuficientes ante el volumen de personas que necesitan ayuda. En cualquier caso, resulta insuficiente dejar estas labores únicamente en manos de los refugios, puesto que por sus instalaciones no pasa el total del flujo de migrantes.

Asímismo,resulta difícilestablecer un patrón general de la comunicación de los migrantes. Apenas un puñado de ellos acuerda un sistema regular de comunicación con su familia antes de partir. Dependiendo de sus recursos y de los consejos que hayan recibido, pueden llevar consigo un celular y ser capaces de sortear los problemas técnicos que surgen al querer usar un teléfono en otro país. En cualquier caso, el número de migrantes que cuentan con uno en el refugio de Tenosique (sur) es muy 
elevado, más del doble respecto a los indocumentados consultados en el albergue de Saltillo (norte). Como se ha visto, viajar con un teléfono acarrea una serie de peligros graves para los indocumentados por lo que no es común que los lleven si van a subir al tren. Si el transporte es el autobús se considera menos arriesgado llevar el teléfono puesto que hay menos probabilidades de ser asaltado por el crimen organizado salvo cuando ya se está cerca de la frontera con Estados Unidos, en especial en el estado de Tamaulipas (noreste), donde Los Zetas han cometido sus peores atrocidades.

Apenas cinco migrantes habían planeado una estrategia de comunicación para reforzar su protección en la ruta y habían incluso establecido claves para que sus familiares estuvieran seguros de que hablaban con ellos y no con alguien que trataba de suplantarles. Lo más común, en cambio, es que los migrantes se comuniquen cuando se dan las condiciones (recursos + medios), sin una regularidad preestablecida, y que la información relativa a su ubicación exacta, contactos y próximos pasos no sea el centro de las conversaciones. La conciencia de protección es mayor en lo que se refiere al peligro de llevar números telefónicos en los celulares o en papeles. La mayoría trata de aprendérselos de memoria. Así mismo, muchos toman también la precaución de eliminar toda la información que pueden de sus celulares e incluso de desinstalar aplicaciones como Facebook y WhatsApp por temor a que pueda quedar algún rastro.

Tampoco se explotan por ahora las posibilidades de acceso a información a través de Internet. Los centroamericanos no parecen encontrar o estar interesados en sitios electrónicos específicos sobre la migración en México. La gran mayoría de ellos se comunica a través de Facebook por medio de chats privados, sin participar de páginas grupales donde poner experiencias y consejos en común. El uso de Google Maps para guiarse por México o el envío de la ubicación a través de WhatsApp ya son una realidad entre los migrantes pero todavía incipiente. En general, los migrantes consideran que comunicarse en el camino es una prioridad pero a la vez son conscientes de los graves riesgos que puede conllevar, por lo que es esta actividad es un continuo dilema para ellos.

Por ahora no se observa una estrategia coordinada de la acción humanitaria a nivel nacional en México para apoyar con información y medios de comunicación a los migrantes. Las casas refugio tienen unos recursos limitados y no son capaces de brindar una atención individualizada a sus usuarios en este ámbito. A su vez, cada una tiene una política de comunicaciones en 
su interior, por lo que difícilmente los migrantes pueden tener certidumbre de qué medios pueden esperar en cada lugar.

Tampoco existen iniciativas de las autoridades mexicanas o de organizaciones no gubernamentales (ONG) internacionales para atender las necesidades de los migrantes en este ámbito, con la salvedad de las llamadas gratuitas que ofrece la Cruz Roja en algunos refugios.

\section{Referencias bibliográficas}

- ACNUR. (2012). Desplazamiento forzado y necesidades de protección generados por nuevas formas de violencia y criminalidad en Centroamérica. Recuperado de: http://www.acnur.org/index.php?id=872\&tx_news_ pi1\%5Bnews\%5D=15374\&tx_news_pi1\%5Bcontroller\%5D=News\&tx_ news_pi1\%5Baction\%5D=detail\&cHash=1f0b59122e8fbd0a6b144bd546 b3025f

- Comisión Interamericana de Derechos Humanos (CIDH). (2015). Situación de Derechos Humanos en México. Recuperado de: http://www.oas.org/es/cidh/ informes/pdfs/mexico2016-es.pdf.

- Federación Internacional de Sociedades de la Cruz Roja y la Media Luna Roja (IFRC). (2013). World Disasters report. Focus on technology and the future of humanitarian action. Recuperado de: http://www.ifrc.org/PageFiles/134658/ WDR\%202013\%20complete.pdf .

- Meier. P. (2015). Digital Humanitarians. How Big Data is changing the face of humanitarian response. Boca Raton: CRC Press.

- Migration Policy Institute. (2015). Migrants deported from the United States and Mexico to the Northern Triangle: a statistical and socioeconomic profile. Recuperado de: http://www.migrationpolicy.org/research/migrantsdeported-united-states-and-mexico-northern-triangle-statistical-andsocioeconomic

- OCHA (Oficina de Coordinación de Asuntos Humanitarios de Naciones Unidas). (2012). Humanitarianism in the network age. Consultado el 10 de julio de 2016. Recuperado de https://docs.unocha.org/sites/dms/Documents/WEB\%20 Humanitarianism\%20in\%20the\%20Network\%20Age\%20vF\%20single.pdf.

- ONU. (2015). Ban advierte sobre la violencia en Triángulo Norte de Centroamérica. Recuperado de: http://www.un.org/spanish/News/story. asp?NewsID=31520\#.WEc2KdxStSt.

- Paullier, J. (24 de mayo de 2016). ¿Abandonados a su suerte: por qué México 
no les da protección a los niños migrantes de Centroamérica? BBC Mundo. Recuperado de: http://www.bbc.com/mundo/noticias/2016/05/160519_ mexico_centroamerica_migracion_ninos_invisibles_aw

- WOLA. (2015). Un camino incierto. Justicia para delitos y violaciones a los derechos humanos contra personas migrantes y refugiadas en México. Recuperado de: https://www.wola.org/wp-content/uploads/2015/11/Uncamino-incierto_Nov2015.pdf.

\section{Notas}

1 Periodista y estudiante de la maestría en Acción Internacional Humanitaria. Universidad de Deusto, España

2 La Secretaría (ministerio) de Gobernación informó que 198,141 extranjeros fueron detenidos y entregados a las autoridades migratorias para su deportación en 2015, de los cuales 177,949 eran originarios del Triángulo Norte.

3 Entrevista con Julio Antonio Ortiz Lara, coordinador del Programa de Asistencia Humanitaria a Personas Migrantes y coordinador del Restablecimiento de contacto entre familiares en Tenosique de la Cruz Roja mexicana, 9 de septiembre de 2016. 